\title{
El movimiento McOndo y la poética de Rodrigo Fresán, una puesta en perspectiva
}

\author{
McOndo muǵimendua eta Rodrigo Fresánen poetika, ikuspeǵi bat \\ The McOndo movement and the poetics of Rodrigo Fresán, an overview
}

\author{
Manuel Domínguez Solís \\ Universidad Nacional Autónoma de México \\ dosmanuels@gmail.com \\ https://orcid.org/0000-0002-1973-2282
}

Recibido / Noiz jaso den: 15/05/2020

Aceptado / Noiz onartu den: 01/09/2020

\section{Resumen}

La presente investigación tiene por objetivo analizar el lugar que ocupó el movimiento literario McOndo ante la crítica, sus tensiones con respecto al canon y la problemática de lo nacional y lo cosmopolita, poniendo en perspectiva la poética de uno de los autores que formaron parte, en su momento, de la antología y movimiento ya mencionado llamado McOndo. A partir del método analítico, la presente investigación busca dar cuenta de las tensiones que se gestan tras el surgimiento de un movimiento contestatario como lo es McOndo, contrastando opiniones y demostrando la marginalidad ante la crítica de ciertos autores como el propio Rodrigo Fresán. Así, a partir del análisis de la poética de Fresán, podemos observar su lugar con respecto al canon y la crítica en cuanto a temas y problemáticas planteadas desde la literatura..

\section{Palabras clave}

Literatura latinoamericana, McOndo, Rodrigo Fresán, literatura nacional, literatura cosmopolita, irrealismo lógico.

\section{Sumario}

1. El DEVENIR MCONDO; LA TENSIÓn ENTRE LO NACIONAL Y LO COSMOPOLITA. 1.1. Las posturas críticas con respecto a McOndo. 2. LA POÉTICA DE RODRIGO FRESÁN; EL IRREALISMO LÓGICO. 2.1. La poética de Rodrigo Fresán, McOndo revisitado. REFERENCIAS. 


\begin{abstract}
Laburpena. Ikerketa honen helburua da McOndo literatura-mugimenduak kritikaren aurrean izan zuen lekua aztertzea, bai eta nazionala eta kosmopolita denaren kanonari eta problematikari buruzko tentsioak ere, eta McOndo izeneko antologia eta mugimenduan parte hartu zuten autoreetako baten poetikari buruzko ikuspegi bat eskaintzea. Metodo analitikotik abiatuta, ikerketa honek McOndo bezalako mugimendu kontestatario bat eratu eta gero sortzen diren tentsioen berri eman nahi du, iritziak kontrastatuz eta zenbait autorek kritikaren aurrean zuten marjinaltasuna erakutsiz, hala nola Rodrigo Fresán. Hala, Fresánen poetikaren azterketatik abiatuta, kanonari eta kritikari buruz duen tokia ikus dezakegu, literaturatik planteatutako gai eta arazoei dagokienez.
\end{abstract}

Gako hitzak. McOndo, Rodrigo Fresán, literatura nazionala, literatura kosmopolita, irrealismo logiko.

\begin{abstract}
The aim of this research is to study the place occupied by the literary movement McOndo in the eyes of the critic, the problems with regard to the issue of the canon and nationalism and cosmopolitism as literary topics. In order to do that the research is going to put into perspective the poetics of Rodrigo Fresán, one of the authors who was part of the socalled movement McOndo. Using the analytic method, this research recounts the critical problems caused by the emergence of a literary movement like McOndo. The contrast of opinions and the demonstration of the marginality of an author like Rodrigo Fresán are part of this research. In general, regarding to the literary issues shown in the poetics of Rodrigo Fresán, this research allows to study his place in the canon and the critical opinion.
\end{abstract}

Keywords. Latin American literature, McOndo, Rodrigo Fresán, national literature, cosmopolitan literature, logic irrealism.

\section{El devenir McOndo; la tensión entre lo nacional y lo cosmopolita}

McOndo es una antología editada por los escritores chilenos Sergiio Gómez y Alberto Fuguet que reunió relatos de autores hispanoamericanos emergentes, tales como Edmundo Paz Soldán, Rodrigo Fresán, Ray Loriga, José Ángel Mañas y David Toscana, entre otros, cuyas poéticas reflejan una tendencia cosmopolita e incorporan la cultura de lo audiovisual como elemento narrativo, contraponiéndose así al canon del realismo mágico ${ }^{1}$ imperante en la literatura hispanoamericana de la época y suscribiéndose como un movimiento que buscaba mostrar la alteridad que hay en Latinoamérica, más allá del folclor que usualmente exporta, en términos literarios, esta región geográfica.

Así, la antología McOndo dio pie a un movimiento literario cuya propuesta se centró en mostrar las repercusiones del contacto entre lo hispanoamericano y la globalización, lo cual implicó un cambio de paradiǵma en la concepción literaria de Hispanoamérica, vista ya no sólo como un producto del realismo mágico, sino

1 En el prólogo a McOndo Fuguet y Gómez relatan el rechazo de la poética de McOndo porque «poseen el estiǵma de carecer de Realismo mágico [...], el rechazo va por faltar al saǵrado códiǵo del Realismo mágico. El editor despacha la polémica arǵuyendo que esos textos bien pudieron ser escritos en cualquier país del primer mundo» (Fuguet y Gómez, 1996, p. 10). 
como una literatura que tiende a incorporar en su discurso las narrativas del cine, la música pop, las series y los programas televisivos; los mass media y la cultura emergente de lo audiovisual que llegaba principalmente de Estados Unidos y que, como mencionan Fuguet y Gómez en el prólogo de la antología McOndo: «coloniza nuestros inconscientes» (Fuguet y Gómez, 1996, p. 15) ${ }^{2} \mathrm{Tal}$ es el caso del escritor arǵentino Rodrigo Fresán, quien contribuyó al volumen McOndo con el cuento Señales captadas en el corazón de una fiesta, y cuya poética de su obra está ligada a los intereses literarios de $\mathrm{McOndo}$, haciéndolo formar parte de este movimiento ${ }^{3}$. Por ello, la revisión de los intereses de $\mathrm{McOndo}$ como movimiento y su recepción por parte de la crítica son una forma de comprender la tradición literaria en la que se suscribe la poética de Rodrigo Fresán, dado que son problemáticas que tocan directamente su escritura.

De esta manera, como señalan Alberto Fuguet y Sergiio Gómez en el prólogo de $\mathrm{McOndo}$, el rechazo de la literatura latinoamericana que no mostrara rasgos relativos al realismo mágico se evidenció en el International Writer's Workshop de la Universidad de Iowa, un taller de escritura al que acudían editores importantes de todo el mundo. Ante este rechazo nació la antología McOndo, cuyo principal antecedente fue la antología Cuentos con Walkman. La diferencia entre estas dos colecciones es que la primera sólo reunía a escritores chilenos menores de 25 años, mientras que $\mathrm{McOndo}$ reunió a autores de todo Latinoamérica. Además, los intereses eran compartidos, tal y como señalan Fuguet y Gómez en el prólogo a la antología McOndo: «la moral walkman es una nueva generación literaria que es post-todo: post-modernismo, post-yuppie, post-comunismo, post-babyboom, post-capa de ozono. Aquí no hay realismo mágico, hay realismo virtual» (p. 10).

Por lo tanto, hablar de $\mathrm{McOndo}$ es remitirse al movimiento que hizo explicito su descontento por el canon que impuso el realismo Mágico de Gabriel García Márquez y que a su vez generó un rechazo por parte de la crítica. Si bien el cosmopolitismo que impera en su poética les fue muy criticado, este aspecto se convirtió en un factor cuyo antecedente es la época de la Colonia, donde había ya una imposición por parte del colonizador, quien dictaba una forma de ser y una tendencia a seguir; donde las diferencias entre débil y fuerte, reconocido e ignorado, políticamente hablando, eran cada vez más explícitas y empezaban

2 Las citas subsecuentes referidas a la antología McOndo serán indicadas únicamente con el número de páǵina.

3 Tomando en cuenta lo que menciona Macías de Yoon en su texto La fiebre de las antologías: narrativa hispanoamericana en tránsito al siglo XX, McOndo tuvo una fuerte influencia en las antologías posteriores a su publicación, tales como Las horas y las hordas, editada por Julio Ortega, y Líneas aéreas, por Eduardo Becerra; además de una antología más editada por Alberto Fuǵuet y Edmundo Paz Soldán: Se habla español, que incluye autores de habla hispana residentes en Estados Unidos, mostrando parte de la alteridad latina ya mencionada (Yoon, 2012, p. 442). 
ya a forjar el canon literario en Hispanoamérica. Un ejemplo de este problema es abordado por Pedro Henríquez Ureña en su texto Seis ensayos en busca de nuestra expresión, donde se propone la elección del español por parte de los latinoamericanos como una problemática identitaria primigenia: «No hemos renunciado a escribir en español, y nuestro problema de la expresión original y propia comienza ahí. Cada idioma es una cristalización de modos de pensar y de sentir, y cuanto en él se escribe se baña en el color de su cristal» (Ureña, 2006, p. 9).

Es por ello que a lo largo de la historia de la literatura hispanoamericana se pueden encontrar diversos antecedentes a movimientos como McOndo y Crack ${ }^{4}$, respectivamente. Lo que estos dos movimientos defendían en común era el carácter universal de la literatura, optando por la inclinación individual del autor por encima de lo colectivo y lo impuesto por una sociedad; es decir la suplantación del interés en la identidad nacional por un interés personal, ligado principalmente a la libre elección del tema literario, influenciado en algunos casos por la cultura emergente de lo audiovisual.

De este modo, tomando en cuenta que toda tradición literaria se forja dentro de la tradición misma, es decir, que ningún movimiento literario puede nacer por sí solo, sin depender ni diferenciarse de otra tradición que lo antecedió y que termina por definirlo, podemos remitirnos al texto de Ángel Rama, Transculturación narrativa en América Latina, donde, en una de las tesis que defiende, el autor señala el carácter internacional de la literatura latinoamericana como registro primigenio, tal y como lo demuestra la cita siguiente: «En la originalidad de la literatura latinoamericana está presente, a modo de guía, su movedizo y novelero afán internacionalista, el cual enmascara otra más vigorosa y persistente fuente nutricia: la peculiaridad cultural desarrollada en lo interior» (Rama, 1982, p. 12).

Ante este carácter internacional de la literatura latinoamericana o la búsqueda del mismo, Ángel Rama señala la problemática que aún atañe a la creación y a la crítica literaria: la elección entre lo nacional y lo internacional como estilo e ideología. Con respecto a esto, Rama enlista una serie de registros literarios tales como el movimiento modernista encabezado por el autor Rubén Darío, cuya principal característica era el cosmopolitismo; por otra parte, menciona a Manuel Gutiérrez Nájera, quien, de acuerdo a Rama, «abogaba por cualquier escenario del universo» (Rama, 1982, p. 14). Otro registro mencionado en el texto de Rama,

4 El movimiento del Crack fue presentado en 1996 con el texto Manifiesto Crack, publicado en la revista Lateral. Revista de Cultura. Al iǵual que McOndo, el movimiento del Crack rechazaba el canon mágicorealista posterior a García Márquez. Ante esto Macías de Yoon dice lo siguiente: «En el manifiesto señalaban a un tiempo el interés por Onetti y Cortázar mientras proponían «una reacción contra el agotamiento» ante el cansancio de que la gran literatura latinoamericana y el dudoso realismo mágico se hubieran convertido, para nuestras letras, en máǵiquismo trágico» (Yoon, 2012, p. 446). 
ligado a la concepción universal de la literatura, es la literatura fantástica, desarrollada por Jorge Luis Borges (1989), llamado por Ángel Rama en Los contestatarios del poder: el maestro del cosmopolitismo vanguardista.

Por el contrario, existen movimientos literarios que durante la historia de la literatura latinoamericana se han opuesto al cosmopolitismo y a la internacionalización, tales como la narrativa social, señalada también por Ángel Rama, y criticada por Alejo Carpentier, escritor mágico-realista inteǵrante del movimiento literario llamado Boom Latinoamericano, quien señala lo siguiente en el texto Los pasos recobrados: ensayos de teoría y crítica literaria:

La época 1930-1950, se caracteriza, entre nosotros, por un cierto estancamiento de las técnicas narrativas. La narrativa se hace generalmente nativista. Pero en ella aparece el factor nuevo de la denuncia. Y quien dice denuncia dice politización. [...] En la novela, la época 1950-1970 se caracteriza por un deliberado abandono del relato de tipo nativista, y la afirmación y búsqueda de nuevas técnicas narrativas. (Carpentier, 2003, p. 188)

Otro contraste señalado por Ángel Rama, relacionado con lo nacional y lo cosmopolita como dicotomía, es el conflicto entre el vanguardismo y el regionalismo. Con respecto a esta problemática es señalada la postura de Horacio Quiroga ante el movimiento regionalista imperante; una postura que bien puede ser vista como un antecedente del movimiento McOndo: rebelarse contra un canon establecido, carente o agotado en sus expresiones literarias posteriores a su principal época de resplandor, y cobijado bajo el manto de la defensa de lo nacional, los valores y las tradiciones patrióticas. Rama, al remitirse a Horacio Quiroga, cita un fragmento de su texto Ante el tribunal, donde el escritor uruguayo expresa su descontento ante la reprobación de sus intereses literarios íntimamente ligados a su personalidad, hecho que también puede considerarse como un antecedente de movimientos como McOndo y Crack, donde tienen prioridad los intereses personales y el forjamiento de una individualidad por encima de lo establecido social y culturalmente hablando. Con respecto a la postura de Horacio Quiroga y la tensión provocada entre lo canónico y lo anti-canónico, en este caso lo regionalista y lo vanǵuardista, Ánǵel Rama menciona que:

El tono liviano no esconde la amargura de una batalla a la que elusivamente contribuyó en los años 1928 y 1929, con una serie de textos sobre su arte narrativa y sobre los narradores-modelo, desplegando su Parnaso: Joseph Conrad, William Hudson, Bret Harte, José Eustasio Rivera, Chejov, Kipling, Benito Lynch, etcétera. (Rama, 1982, p. 21)

Además, hay otras expresiones literarias que forman parte de los antecedentes que terminaron por influir en la publicación de McOndo, cuyas poéticas ya 
presentaban unas propuestas literarias distintas a las establecidas por el canon mágico-realista. Un ejemplo de ello es la antología Novísimos narradores hispanoamericanos en marcha, editada por Ángel Rama, donde ya se pueden observar algunos elementos que la ligan a lo expresado en McOndo. Ante esto Macías de Yoon señala lo siguiente en su texto La fiebre de las antologías: narrativa hispanoamericana en tránsito al siǵlo XXI: «Alguunos elementos a destacar en dicha antología son el abanico generacional comprendido, la influencia de los mass media subrayada en el prólogo, la (in)dependencia en relación con la generación del Boom, además del peso de la editorial y del compilador». (Yoon, 2012, p. 444)

En esta antología se encuentran textos de Juan José Saer, Mario Szichman, Reinaldo Arenas, Antonio Skármenta, Jorge Ibarguengoitia, José Agustín, Eduardo Galeano, Alfredo Brice-Echenique, Manuel Puiǵ, considerado, este último, por Rodrigo Fresán como el padre de McOndo, y un autor que influyó directamente sobre la poética McOndiana por abducir en su literatura las expresiones de la cultura popular, principalmente el cine. Al respecto, Rodrigo Fresán dice lo siguiente en una entrevista realizada por Kelly Harǵrave y Georgiia Smith Seminet perteneciente al texto De Macondo a McOndo: nuevas voces en la literatura latinoamericana:

McOndo está luchando contra el estereotipo yanqui/europeo que tienen de nosotros. Creo que Manuel Puig es el padre de McOndo. Lo considero muy argentino, muy latinoamericano. Básicamente la gracia de él es cómo la cultura popular, en su caso las películas antiguas o los boleros o el tango, influía a la gente del pueblo. Se les hacía soñar. (Hargrave y Smith, 1998, p. 19)

Un ejemplo que hace más evidente la relación entre McOndo y la antología Novísimos narradores hispanoamericanos en marcha lo podemos encontrar en el prólogo de esta, titulado Los contestatarios del poder, donde Ángel Rama, el antologador, detecta en la poética de los novísimos una inclinación por la urbanización y sus implicaciones como tema literario. Ante esto menciona lo siguiente:

La transculturación producida en las grandes ciudades latinoamericanas por la influencia de la cultura masiva de Estados Unidos generando modos específicos de innegable vulgaridad y vigor. Fuentes, o García Márquez o Donoso, leyeron la mejor narrativa norteamericana dentro del vasto conjunto de la literatura vanguardista mundial; los jóvenes posteriores vivieron el cine, la televisión, el rock, los jeans, las revistas ilustradas, los super mereados, la droga, la liberación sexual, los drugstores, que inundaron la vida latinoamericana con profunda incidencia en las capas más populares, menos intelectualizadas y dispuestas a resistir la avalancha que los sectores cultos impregnados todavía de tradiciones europeas. (Rama, 1981, p. 23) 
Del mismo modo, y siguiendo el enfoque que conforma el contexto precedente que influyó al movimiento McOndo, podemos remitirnos al movimiento Beatnik de los años 60's y 70's en Latinoamérica, el cual ya tenía esa condición de apropiarse de un estilo extranjero, siguiendo, hasta cierto punto, una moda en cuanto a valores extraliterarios se trata. Así, se conoce como beatniks a aquellos movimientos literarios en Hispanoamérica que trataban de emular los estilos de vida y las tendencias ideológicas de la literatura beat estadounidense, de manera que la importancia del individuo, sus gustos y su forma de relacionarse con los demás a través de estos, cobró fuerza e influyó directamente en movimientos como el de McOndo.

Por lo tanto, si se toma en cuenta el caso de la tendencia beatnik en México, conocida como Literatura de la Onda, la cual fue una corriente cuyas obras tenían la influencia de la cultura popular, a la que se puede concebir bien como un antecedente de la tradición literaria de la que formaría parte el movimiento McOndo, o como una antítesis del mismo, dada su relación con el capital cultural, podemos poner en perspectiva la opinión de Kelly Hargrave y Georgia Smith en De Macondo a McOndo: nuevas voces en la literatura latinoamericana, donde señalan que:

En la narrativa de la onda, igual que en los cuentos de McOndo, las manifestaciones del capitalismo no están rechazadas sino integradas en la existencia cotidiana dentro de la ficción. Por otra parte, mientras la literatura de la onda (por ejemplo, Gustavo Sáinz y José Agustín) representa a una contra o anticultura, en McOndo los cuentos no van en contra del estatus quo. Los personajes principales de la antología pertenecen a una clase media o media alta y no buscan cambiar la sociedad ni subvertir los valores sociales. (Hargrave y Smith, 1998, p. 16)

Además de estos registros literarios ya mencionados, se puede poner en perspectiva el trabajo de autores como Octavio Paz, Juan García Ponce, Sergio Pitol y Pablo Neruda, entre muchos otros, cuyo cosmopolitismo formó parte importante de sus obras e ideologías. Incluso el movimiento del Boom en Hispanoamérica, donde surgió el registro mágico-realista explotado por Gabriel García Márquez fue esencialmente un movimiento cosmopolita, con técnicas narrativas provenientes de autores extranjeros como William Faulkner, Mark Twain, Ernest Heminǵway, James Joyce, Jean Paul Sartre, entre muchos otros.

Por lo tanto, al hablar de McOndo surgen dos posturas antagónicas; por un lado, la recepción de la crítica ante un movimiento literario visto como un síntoma más del neoliberalismo imperante en la sociedad latinoamericana finisecular; y por el otro, la revisión del cambio de paradiǵma que presenta la propuesta literaria de este movimiento; una propuesta literaria que no puede ser comprendida 
sino como el proceso de formación de una tradición cosmopolita, cuyo origen puede encontrarse en la elección del español como lengua por encima de alǵuna lengua autóctona, pasando por los diversos movimientos literarios forjados en Latinoamérica que defendían un cosmopolitismo que ayudara a desarrollar mejor su literatura, y presentando características literarias generadas por el fenómeno de la globalización con el fin de expresar su propia visión de Hispanoamérica.

De esta manera se puede vislumbrar la tradición literaria a la que pertenece Rodrigo Fresán, cuya expresión literaria está vinculada a los estatutos principales de $\mathrm{McOndo}$, de manera que la poética de su obra, donde se encuentran títulos tales como Historia argentina, Jardines de Kensignton, El fondo del cielo, Mantra, La parte inventada, entre otros, puede ser puesta en perspectiva no sólo con respecto a su recepción crítica, sino a la del movimiento McOndo mismo y sus implicaciones.

\subsection{Las posturas críticas con respecto a McOndo}

El movimiento McOndo no ha sido bien aceptado por la crítica; esto causado principalmente por su postura anticanónica, es decir, su visión internacional de la literatura, la cual inteǵra en sus intereses literarios la cultura emergente de lo audiovisual, dejando de lado los temas que, desde la perspectiva crítica nacionalista, deberían preocupar a un escritor latinoamericano. En otras palabras, lo que la crítica no acepta, más allá de su propuesta literaria, es su postura y posición extraliteraria. De esta manera, la revisión de la recepción crítica de McOndo permite poner en perspectiva la posición de la poética de Rodrigo Fresán ante el canon y deja ver los contrastes y percepciones en torno a las problemáticas antes abordadas con respecto a lo nacional y lo cosmopolita.

Así, McOndo está conformado por una generación de escritores de clase media-alta y clase alta que desde pequeños vivieron el cosmopolitismo que irían a mostrar en su literatura. En el caso del escritor argentino Rodrigo Fresán, por ejemplo, tal y como lo señala L. Gaffoglio en su artículo «Rodriǵo Fresán: escribir hoy es más arduo, cansador y lento, pero también es más interesante», se trata de un hijo de intelectuales, cuyo padre fue un ilustrador famoso relacionado con el mundo de los libros, hecho que hizo que escritores y editores frecuentaran su vida cotidiana cuando apenas era un niño, además de tener acceso a todos los ejemplares de la colección Minotauro, centrada en la Literatura fantástica y de cienciaficción, ǵracias a la relación entre su madre y Francisco Porrúa, fundador de esta colección y editor de obras como Cien años de soledad y Rayuela (Gaffoglio).

Alberto Fuguet, por su parte, escribía textos en inglés y los publicaba en importantes medios de comunicación como The New York Times y Newsweek, entre otros. Lo anterior, aunado a su predilección por las culturas extranjeras, 
usualmente anǵlosajonas, por encima de las locales, fue lo que llevó a la crítica, en su mayoría, a reprobar este movimiento; de ahí que la atención académica hacia las obras de autores como Rodrigo Fresán, sean muy escasas, a pesar de contar con múltiples reediciones.

Ante esto, se retoma el debate generado entre lo nacional y lo cosmopolita visto como una tensión entre canon y anti-canon; con respecto a esta problemática se encuentra la crítica de escritores como Jorge Fornet, quien en su texto Nuevos paradigmas en la narrativa latinoamericana define a McOndo como un síndrome literario neoliberal por el hecho de dejar de lado la literatura de compromiso, y no ocuparse de los temas que, desde su punto de vista, tanto atañen y preocupan a Latinoamérica, además de criticar la postura de Fuguet y Gómez en el prólogo de $\mathrm{McOndo}$, donde se dice que: «Si hace unos años la disyuntiva del escritor joven estaba entre tomar el lápiz o la carabina, ahora parece que lo más angustiante para escribir es elegir entre Windows 95 o Macintosh» (Fornet, 2005, p. 13). Fuguet y Gómez se mofan de lo que rechazan, es decir, de la tendencia a seguir escribiendo realismo mágico después de García Márquez, y seguir retratando el exotismo de lo autóctono y la solemnidad de la identidad patriótica, envuelta en un aura de presencia mítica desde la comodidad de un Mac o una PC. Por su parte Jorge Fornet prioriza las problemáticas locales y señala y critica la postura de $\mathrm{McOndo}$ arǵumentando lo siǵuiente:

Situar en el centro de la angustia actual la opción entre Windows y Macintosh -más allá de la caricaturesca y falsa disyuntiva entre tomar el lápiz y la carabina-, es una banalización más jocosa que real. La violencia, la corrupción, el narcotráfico, la emigración, el SIDA, son temas que siguen «angustiando»a muchos de los escritores de hoy y algunos de los cuales asoman en las propias páginas de McOndo. (Fonet, 2005, p. 6)

Dado lo anterior, se puede añadir, a manera de diálogó, la opinión de Iǵnacio Padilla en su texto McOndo y El Crack: dos experiencias grupales publicado en el año 2004, donde diserta sobre las ideas y posturas propuestas en el prólogo de McOndo; una opinión que marcará ya una tensión entre lo cosmopolita, en su variante jocosa o paródica, y lo nacionalista y su inclinación por la literatura de compromiso; cuestiones que ya dejan ver las lecturas contrapuestas en torno a las implicaciones del ser latinoamericano por parte de movimientos como McOndo y Crack, por un lado, y de la crítica, por el otro:

Creo que es imperioso encarecer el carácter profundamente lúdico y contradictorio de McOndo y el Crack. [...] De ahí que, entre otras cosas, tanto la antología de McOndo como el manifiesto del Crack parezcan y estén lógicamente llenos de contradicciones, tan naturales cuando se habla desde el mundo del revés. (Padilla, 2004, pp. 141-142) 
Con respecto al diálogo antes mencionado entre Jorge Fornet e Iǵnacio Padilla, se vuelve evidente, en primera instancia, la postura canónica latinoamericana; es decir, la literatura de compromiso, los valores nacionales, la identidad como pueblo, lo patriótico y en segunda instancia, la inmersión en el marǵen del movimiento McOndo. En este caso, lo que los marǵina es su concepción de la literatura vista como un valor universal, además de presentar una alternativa a los registros antes mencionados relacionados con la nación como tema literario, lo que implica una inclinación por aquellos temas que personalmente les interesan a los autores, de manera que las cuestiones políticas que atañen a sus países de origen pueden ser ignoradas o escritas bajo la perspectiva de la individualidad.

De la misma manera, retomando el paradiǵma del realismo mágico como canon imperante en Hispanoamérica, y en cuanto a los procesos de marketing se trata, Jorge Fornet critica la forma de operar del movimiento McOndo; una forma que, según él, copia los estándares de publicación del Boom, por lo tanto considera que el movimiento McOndo cae en una contradicción: «No deja de resultar una ironía que intentando combatir un Macondo de exportación, Fuguet haya acuñado un McOndo for export» (Fornet, 2005, p. 8).

La ironía que Fornet señala no puede ser válida porque, como ya se dijo anteriormente, McOndo aboga por el carácter universal de la literatura, lo que implica un lector modelo, en términos de Eco, ya no hispanoamericano, sino internacional; hecho que ha llevado a la mayoría de estos autores a pasar desapercibidos en cuanto a su identidad geográfica se trata. Además, el McOndo for export es precisamente lo que busca este movimiento; es decir, acabar con la concepción de América Latina como una provincia folclórica, y presentarla, mediante una propuesta literaria, como una pieza más del fenómeno ǵlobalizador, tal y como lo explican Fuguet y Gómez en el prólogo de la antología McOndo:

En nuestro McOndo, tal como en Macondo, todo puede pasar, claro que en el nuestro cuando la gente vuela es porque anda en avión o están muy drogados. [...] Acá los dictadores mueren y los desaparecidos no retornan. El clima cambia, los ríos se salen, la tierra tiembla y Don Francisco coloniza nuestros inconscientes. (p. 8)

Igualmente, Diana Palaversich en su texto Rebeldes sin causa. Realismo mágico vs realismo virtual se une a la crítica de Fornet en cuanto al modo de operar de McOndo; es decir, utilizar los mismos métodos de marketing que el Boom. Ante esto comenta lo siguiente: «Que McOndo se publique en España y de allí se «exporte» y disemine por América Latina parece repetir la trayectoria del Boom que para lograr mayor distribución continental y ser reconocida en los respectivos países de origen debía publicarse fuera del mismo» (Palaversich, 2000, p. 55). 
Además, el texto de Palaversich vincula los postulados y los objetivos de McOndo, especialmente refiriéndose a la poética de Alberto Fuguet, con el neoliberalismo que está empezando a expandirse por Latinoamérica, al señalar aspectos extraliterarios como el hecho de que se trate de «una generación de jóvenes de clase media y media alta criada en centros metropolitanos y formada por el cine y la televisión estadounidenses» (Palaversich, 2000, p. 57). Así, se hacen evidentes dos realidades sociales, de muchas posibles, en la Latinoamérica de fin de siglo: por una parte, la Latinoamérica autóctona, tradicional, folclórica y marginada; y por otra, la Latinoamérica trastocada por la ǵlobalización. Sin embargo, estas dos posturas adversas son complementarias para la conformación de una sociedad, tal y como lo explica Ángel Rama en la siguiente cita extraída del texto Los contestatarios del poder:

Es dentro de esa serie cultural y no fuera, donde las obras literarias conquistan su plenitud de sentido, pues es allí que las microestructuras que son esas obras, resultan alimentadas, fundadas y legitimadas por la macroestructura cultural a la que pertenecen. La cual, por cierto, no es una y coherente para toda América Latina, puesto que el continente está conformado por plurales áreas culturales, las cuales, además, se integran con variadas estratificaciones, en la misma región, en el mismo país, a veces en la misma ciudad. (Rama, 1981, pp. 13-14)

La crítica y el movimiento McOndo tendrán posturas distintas, en su mayoría extraliterarias, con respecto a las situaciones sociales antes mencionadas, de manera que el movimiento McOndo será considerado como anticanónico; sin embargó, su condición de marǵinalidad es cuestionable.

Con respecto a esto se puede observar que se trata de una marginalidad matizada, ya que cuenta con diversas perspectivas. Primero, se le puede considerar como un movimiento marǵinal ante la crítica, ya que se trata de una literatura que se sitúa fuera del canon, saliéndose del mismo, incluso, de forma tajante tras expresar su rechazo al realismo mágico imperante y proponer un cambio de paradiǵma relacionado con la poética del mass media, otorgándole valores estéticos a la cultura de lo audiovisual. Esto es lo que ha provocado que hablar de McOndo sea hablar de su condición política, es decir, extraliteraria y sociológica, y no de su propuesta literaria.

Ante esto, podemos encontrar estudios como el realizado por Claudio E. Benzecry, titulado El almuerzo de los remeros. Profesionalismo y literatura en la década de los '90, donde a partir de las presentaciones de algunos libros de Rodrigo Fresán, da cuenta del centro y la periferia que impera en su mundo literario, el cual está formado en su mayor parte por escritores pertenecientes al movimiento McOndo, como Alberto Fuguet, Juan Forn y Ray Lóriga. En este estudio, Benzecry sitúa a estos autores, además de algunos otros, tales como Guillermo 
Saccomanno y Alan Pauls, en el centro; en la periferia sitúa a aquellos aspirantes a ocupar los lugares que ocupan los escritores centrales. Por lo tanto, de acuerdo con esta perspectiva, el movimiento McOndo y su poética no podría ser considerada marǵinal, ya que como señala Benzecry son escritores que, a través de un capital social sólido, han constituido un capital literario consolidado (Benzecry, 2015, p. 25). Por lo tanto, es gracias a este capital literario y social que se explican las abundantes publicaciones y reediciones de sus textos, al contrario de lo que sucede con textos marǵinales. Así, la marǵinalidad, en literatura, tiene que ver con la adhesión o separación al canon imperante, y de los capitales sociales y literarios que harán posible las publicaciones y reediciones.

Por otra parte, siguiendo con el tema de la marginalidad, Diana Palaversich en Rebeldes sin causa. Realismo mágico vs Realismo virtual considera que la propuesta de McOndo es una propuesta que más allá de evolucionar, retrocede con respecto al realismo mágico, y que la marginalidad que se atribuyeron después de su rechazo en la International Writer's Workshop de la Universidad de Iowa es una treta para presentarse como un movimiento anticanónico e innovador, cuando en realidad, considera, son temas ya harto elaborados. Así lo explica en la siguiente cita: «Esta representación falsa del realismo mágico como mainstream literario par excellence les permite concebirse a sí mismos como rebeldes que subsisten y escriben en las márgenes del canon» (Palaversich, 2000, p. 68).

De tal manera que, con respecto a la marginalidad del movimiento McOndo, se puede observar que se trata de una marginalidad ante la crítica. La crítica no lo acepta ni siquiera como un contra-canon, considerándolo como un movimiento carente del bagaje literario necesario para poder romper con un paradiǵma tan establecido y representante como es el realismo mágico. Ante esto se pueden considerar las reflexiones de Harold Bloom propuestas en su texto The western canon en torno a lo canónico, ligado a conceptos como estética, originalidad e inmortalidad; jerarquizando la percepción individual por encima de la social. De esta manera una estética de lo audiovisual resulta imposible de admitir ante los ojos del canon, ya que, según la crítica, aboga por la inmediatez y pertenece a un estrato social, y no individual. Sin embargo, Harold Bloom reconoce el cambio de paradigma producido a causa de la ruptura entre el discurso histórico y el literario, aspecto que impera en McOndo dada su propuesta de separar literatura y nación.

De acuerdo a lo dicho hasta este momento, el movimiento McOndo no está en contra de la poética del realismo mágico de García Márquez, sino en contra de la concepción existente de la literatura latinoamericana, ligada únicamente al realismo mágico, es decir, la imagen exterior que se tenía de Latinoamérica era una imagen concebida a partir del canon mágico-realista, cuando en realidad había otros tipos de literatura emergentes que no tenían la atención debida a causa de su situación anti-canónica, como señala Edmundo Paz Soldán, escritor boliviano, 
participante de la antología McOndo, en su texto Between tradition \& innovation. The new Latin American narrative, donde propone una mirada de respeto hacia las tradiciones literarias pasadas y hacia los propios clásicos, y ve como algo sano la irreverencia de autores emerǵentes como Mayra Santos, Rodrigo Fresán, Alberto Fuguet, Iván Thays, entre otros: «Traditions that do not constantly renew themselves become stagnant. There is nothing healthier for a culture than an attitude of recognition of the great artistic Works of the past, coupled with a playful irreverence, a constant rejection of that same past» (Soldán, 2004, p. 17).

De esta manera, Paz Soldán, como defensor del movimiento del cual forma parte, remite a la idea de precursor señalada por Harold Bloom en The western canon como fundamental para la formación del canon, dada su condición de intermitencia y constante cambio, relegándole la responsabilidad al lector y su sensibilidad, es decir, a su individualidad. Así, el lector, cara a cara con la obra literaria tiene la posibilidad de forjar un canon o de convertir un contra-canon en canon.

Además, la postura que toma Paz Soldán en su artículo tiene que ver con la concepción antes mencionada de la literatura vista como un valor universal, cuya fuente principal y origen primigenio se encuentra en la biblioteca del autor. Así, la idea de que la biblioteca sea la bandera que defienda el escritor, y por lo tanto sea también una forma de libertad de elección ante los diferentes tipos de registros literarios existentes es otra de las posturas que presenta $\mathrm{Paz}$ Soldán en su texto y que además remite a la posición ya mencionada de Horacio Quiroga ante la literatura regionalista de su época, dejando ver algunas características con respecto al cambio de paradigma en la literatura latinoamericana después del realismo mágico de García Márquez. Un ejemplo de ello tiene que ver con el apunte de Paz Soldán con respecto a la literatura de compromiso como obligación, ante lo cual se pronuncia de la siguiente manera: "As the moral conscience of the nation, the writer has made claim, in the words of Pablo Neruda, that through his or her voice shall speak those who have no voice of their own. Today, we prefer that such an obligation be merly an option for the writers» (Soldán, 2004, p. 18).

Por consiguiente, al poner en perspectiva las posturas opuestas de Paz Soldán y Jorge Fornet, respectivamente, se puede observar un diálogo en torno al cambio de paradigma propuesto por el movimiento McOndo; un cambio de paradigma estudiado y criticado de acuerdo a los conceptos propuestos por Bloom con respecto a lo canónico. Por otra parte, Fornet desacredita al movimiento McOndo por banalizar los problemas reales a los que se enfrenta Latinoamérica, tales como la corrupción, el narcotráfico, la miǵración, la violencia, el SIDA, etc., lo cual remite a la postura de Paz Soldán con respecto a la literatura de compromiso; es decir, la idea propuesta por Pablo Neruda de darle voz a quienes no la tienen a través de la literatura. 
Ante esta postura, Paz Soldán considera un acierto el hecho de que la literatura hispanoamericana expanda sus niveles de discurso, como él mismo lo menciona, además de abrir una brecha más: el papel del escritor ante los mass media y las nuevas tecnologías emergentes y su contacto con la sociedad, lo cual tendrá su mayor expresión en la cultura de lo audiovisual que permearía la poética de McOndo y que resulta ser, para Paz Soldán, una problemática igual de importante que las sugeridas por Fornet, y que, además, considera que no por tratarse de una cultura desechable o mortal, en términos de Bloom, la literatura que hable de ella también tenga que serlo. Para cumplir ese cometido, se proclama tener a una biblioteca como morada y fuente nutricia, tal y como lo menciona en la siguiente cita: «Let us respect and at the same time maintain a playful attitude when it comes to libraries. Let us swarm the video-rental stores and ride the cresting wave of the growing use of the computer and its network of networks» (Soldán, 2004, p. 18).

A este diálogo entre lo nacionalista y lo cosmopolita; lo canónico y lo anticanónico, se adhiere Jorge Volpi con su texto El fin de la narrativa latinoamericana, donde paródicamente cita in extenso el hipotético artículo «Cincuenta años de la literatura hispánica, 2005-2055: un canon imposible», publicado por el también hipotético catedrático de literatura hispánica y chicana Iǵnatius H. Berry, en el cual se pueden ver resumidas las críticas antes citadas que han recibido movimientos como McOndo y Crack, acusando su renuncia a lo nacional y por lo tanto a la búsqueda identitaria de lo latinoamericano, además de su inclinación por la publicidad y el mercado; factores que provocaron, de acuerdo al hipotético H. Berry, la muerte de la narrativa latinoamericana, la cual es concebida no en el sentido de su desaparición, sino de su condición atópica.

De esta manera, y ante el hipotético texto de H. Berry, cuyas posturas están ligadas a las de los críticos antes expuestos que reprueban el movimiento McOndo, Jorge Volpi entra en diálogo argumentando que desde la época de la Colonia en América Latina ha existido una disputa entre los nacionalistas y los cosmopolitas, hecho que pudo verse trazado con los diferentes movimientos literarios antes expuestos, y que formaron parte del devenir McOndo, ante lo cual Volpi afirma que: «frente a la necesidad obsesiva de crear una identidad nacional, los escritores se rebelaron apelando a la comunidad de la lengua, primero, y a la de la cultura, después, para sentirse escritores pertenecientes, con todos los derechos, a la tradición literaria occidental» (Volpi, 2004, p. 40). Con respecto a esta postura, Volpi asegura que «los mejores escritores latinoamericanos han sido, en la mayor parte de los casos, cosmopolitas» (Volpi, 2004, p. 39). Así, el autor defiende a movimientos como McOndo y Crack, del cual formó parte, atribuyéndoles un acierto por seguir la tradición cosmopolita que ha permeado a la literatura latinoamericana desde sus inicios.

Además, dialoga con los críticos que reprueban a McOndo por considerarlo un movimiento preocupado más por lo comercial que por lo literario. Ante esto 
Volpi considera que lo que McOndo y Crack buscaban no era contraponérsele, sino «recuperar su intención original [...], perseguir la misma libertad alcanzada por el Boom» (Volpi, 2004, p. 40).

En términos generales, la crítica simpatiza con el nacionalismo como canon, y por ello reprueba movimientos literarios que tengan que ver con la renuncia a lo nacional, es decir la concepción del cosmopolitismo como calidad inherente a la Literatura. Ante esta tensión entre lo canónico y lo anticanónico, las opiniones se dividen en torno a la siguiente interrogante: ¿Qué postura debe tomar tanto el lector como el escritor latinoamericano ante la cultura de lo audiovisual y lo mass media que nos rodea? Por tratarse de culturas ajenas a Latinoamérica, estas forman parte de la tendencia cosmopolita, contrapuesta a la nacionalista, sin embargó, como señalan Fuguet y Gómez en el prólogo a McOndo: «Temerle a la cultura bastarda es negar nuestro propio mestizaje» (p. 15).

Así, una posible respuesta a la interrogante antes planteada se puede encontrar en la propuesta literaria de Rodrigo Fresán y su novela La parte inventada ya que no sólo reúne las características cosmopolitas expuestas hasta este momento, sino que pone en perspectiva los preceptos de $\mathrm{McOndo}$ a veinte años de su publicación. De esta manera, con su análisis se podrá observar el tratamiento teórico de la cultura de lo audiovisual y lo mass media en literatura, además de cuestionar el lugar que ocupa una obra de esas características en la tradición literaria contemporánea.

\section{La poética de Rodrigo Fresán; el irrealismo lógico}

Rodrigo Fresán contribuyó a la antología McOndo con el relato Señales captadas en el corazón de una fiesta, incluido también en La velocidad de las cosas, donde ya se observa su interés por la representación literaria de la cultura pop y por las nuevas formas de existencia causadas por la globalización y el capitalismo.

Lo anterior propició un cambio de paradiǵma en la literatura Latinoamericana, siendo uno de los objetivos primordiales del movimiento McOndo, el cual se percibe en el paso del realismo mágico y sus coroneles, provincias, hieráticos personajes y malezas indómitas donde el mito se erige como el principal estandarte; al irrealismo lógico, así llamado por el mismo Rodrigo Fresán, donde ya se respira el smog y se va por la calle escuchando en walkman a The pet shop boys; donde las ciudades están invadidas por centros comerciales o malls que dictan la pauta de la moda y el consumo, donde el contacto humano con humano empieza a ser suplantado por la dicotomía humano-máquina.

Así, se desprenden algunas líneas temáticas a seguir dentro de la poética fresaniana; una de ellas es la recurrente relación hombre-máquina, temática vinculada con lo posthumano, es decir, con el surgimiento de una nueva realidad que 
también atañe a las subjetividades latinoamericanas. Ante esta temática, Andrew Brown en su texto Video heads and rewound bodies: ciborgs memories in Rodrigo Fresán and Alberto Fuguet menciona lo siguiente:

In both Mantra and Por favor, rebobinar we see articulations of posthuman identity that begin with the ciborg reality of technological bodies and then situate them not within a history of dictatorship or a present of political and economic abuses but as a reality that requires new mythologies and different ways of remembering individual experience. (Brown, 2010, p. 146)

Esta opinión remite una vez más al relato de Rodrigo Fresán más relacionado con esta poética: Señales captadas en el corazón de una fiesta, donde se cuenta la historia de Willi, el fantasma de un joven homosexual abatido por el VIH, que sigue frecuentando las fiestas a las que iba cuando vivo, utilizando como médium una radio y una televisión, lo cual, además de ser una reflexión sobre lo posthumano señalado por Brown, dada la condición de cyborg del personaje Willi, es un tema que será recurrente en la poética de Fresán.

Además, el abordaje literario del tema de lo posthumano, puede considerarse como una posible respuesta a la interrogante planteada en el capítulo anterior: ¿Qué postura debe tomar tanto el lector como el escritor latinoamericano ante la cultura de lo audiovisual y lo mass media que nos rodea? Ante esto, el mismo Andrew Brown dice lo siguiente:

The narrator does not merely receive the conversations and sounds of the party as signals; he also captures the images, his tired retina is described in its camera-like functions as he looks and fixes each scene, recording it as he did the overheard sounds. This process erases him as a man, making him invisible but also converting him into television. That is, his ability to receive signals makes him more akin to the quotidian device that also receives and fixes image and sound. For that reason, the logical response to the narrator at parties is «zapping»; that is, the other partygoers change him as they would a channel. (Brown, 2010, p. 156)

Así, la idea de la máquina como receptora y productora de señales, y su vínculo íntimo con el hombre contemporáneo, se relaciona directamente con el tema de la memoria ajena propuesto por Ricardo Piglia, quien se remite al relato La memoria de Shakespeare de Jorge Luis Borges para explicar la concepción borǵesiana de la memoria, otorgándole valores tales como la fraǵmentariedad, la artificialidad, y la impersonalidad, tal y como lo describe el propio Borges en la siguiente cita: «A nadie le está dado abarcar en un solo instante la plenitud de su pasado. [...] La memoria del hombre no es una suma; es un desorden de posibilidades indefinidas» (p. 397). Estos valores influirán en la construcción de la 
ficción en las obras de Rodrigo Fresán, específicamente en el empleo de técnicas narrativas tales como el sapping y el cut-up.

De tal manera que el irrealismo lógico propuesto por Fresán, más allá de la mala recepción por parte de la crítica, no es un mero capricho posmoderno, ni un vulgar rechazo de un canon establecido, sino una forma distinta de mirar los fenómenos contemporáneos tales como la globalización y las culturas emerǵentes ya mencionadas de lo audiovisual, desde su puesta en perspectiva con temas como la memoria, la muerte, la realidad, y la literatura misma. El irrealismo lógico pondera la irrealidad sobre la realidad, de manera que el tema literario y su desarrollo rebasan la causa. Así, la internacionalización de la literatura, la búsqueda de una libertad creativa fuera de los cánones establecidos, y por ende de compromisos de tipo geográficos e históricos de que se hablaba en McOndo está sedimentada en la poética del irrealismo lógico.

\subsection{La poética de Rodrigo Fresán, McOndo revisitado}

La poética de la obra de Rodrigo Fresán, como se ha dicho hasta este momento, se puede comprender mejor si se la mira en perspectiva con los postulados y propuestas literarias de $\mathrm{McOndo}$, que si bien la mayoría de los autores que formaron parte en un inicio de esta antología han emprendido caminos distintos, esta ha sido un hito definiendo los intereses literarios de autores como el propio Rodrigo Fresán, quien con una de sus últimas obras, La parte inventada, ratifica la vena Mcondiana de la que proviene, ya que, más allá de la recurrencia de las temáticas que imperan en su poética, la preocupación por las realidades o irrealidades generadas a partir de la tecnología y los nuevos medios de comunicación, y el lugar al que estos han relegado al libro y a las acciones de leer y escribir siguen siendo latentes como en su momento lo fue la cultura del walkman. En La parte inventada se hace más explícita la noción de internacionalización de la literatura que buscaba McOndo; la biblioteca como patria y los escritores como héroes patrios a tal punto que el tema central de esta novela son los mausoleos de un escritor antes de escribir un libro, lo que implica tener como tema central a la literatura misma.

De esta manera, poniendo en perspectiva la propuesta literaria de McOndo con la poética de Rodrigo Fresán podemos encontrar múltiples valores que las emparentan, uno de ellos es el cambio de paradigma que va de lo nacional a lo cosmopolita como registro literario, lo cual se puede ver ejemplificado en la inserción de la cultura pop en el inconsciente colectivo de una nación y sus implicaciones ligadas a los efectos de la globalización y la cultura de masas. Ante esto podemos observar el relato La soberanía nacional de Rodrigo Fresán, incluido en el volumen Historia argentina, donde se narra la historia de tres personajes que 
fueron enviados a la guerra de las Malvinas en el año de 1982, conflicto armado entre las naciones de Argentina y el Reino Unido por disputa de territorio. Entre estos personajes, se encuentra uno que se enlistó de forma voluntaria no por querer luchar por su patria, sino por encontrar en esta acción su única oportunidad de escuchar en vivo a su banda favorita: The Rolling Stones, tal y como se puede observar en la siguiente cita: «Porque la idea es que me lleven prisionero a Londres, esperar que se acabe el tema este de la uar y entonces sí, pase para concierto de los Rolling, y la ǵloria, man. ¿Cómo no iba a aprovechar esta? ¿Cómo los iba a ver a Mic y a Keit si no era así?» (Fresán, 2018, p. 129). De esta manera, Fresán sabotea el discurso oficial y marca una línea literaria alejada de la literatura de compromiso, esto a través de una figura meramente contemporánea: la del fanático. La idea del fanático en la poética de Rodrigo Fresán está vinculada a la concepción de la internacionalización de la literatura; una literatura que, como se quería en McOndo, imita a la literatura y no a la realidad referencial, además de buscar libertad creativa a través del gusto personal ya por escritores, ya por músicos, ya por directores de cine, y cuyos valores principales son la imaginación, la pluralidad de miradas posibles en torno a algo, la inserción en la literatura de discursos ajenos a la misma; en fin, la literatura por la literatura.

De esta manera, la figura del fanático, además de estar ligada a la concepción internacional de la literatura, tiene que ver con un aspecto que le fue muy criticado a McOndo: el paso de lo general a lo particular en cuanto a identidad se trata. Ante esto Jorge Fornet en Nuevos paradigmas en la narrativa latinoamericana considera que:

El gran tema de la identidad latinoamericana (¿Quiénes somos?) pareció dejar paso al tema de la identidad personal (¿Quién soy?). Los cuentos de $\mathrm{McOndo}$ se centran en realidades individuales y privadas. Suponemos que ésta es una de las herencias de la fiebre privatizadora mundial. (Fornet, 2005, p. 6)

Así, el crítico cubano, pondera la literatura de compromiso, y ve como un síndrome neoliberal la propuesta literaria de jerarquizar al individuo y su vínculo con la cultura pop.

Por otra parte, la ausencia de fábula trastoca no sólo al narrador, sino al lector mismo, ya que los mecanismos que hacen posible la poética de Rodrigo Fresán se van revelando dentro de ella misma, volviéndose una amalgama que engloba escritura, lectura e interpretación. De tal manera que la obra es concebida como infinita, es decir, en constante desarrollo. Esta noción de infinitud se puede observar en Mantra, donde el tiempo es concebido como circular, iǵual que la obra, tal como sucede con el calendario azteca.

En suma, la poética de Rodrigo Fresán muestra frecuentemente la influencia McOndiana de la que proviene, incluso en obras más actuales tales como El fon- 
do del cielo y La parte inventada. Se trata de una poética comprometida con la irrealidad, como ya se dijo anteriormente. De esta manera se le da mayor importancia a la imaginación que al compromiso social, además de una propuesta de resignificación de la Historia, ponderando la subjetividad sobre el discurso oficial y dando pie a la inserción de nuevas tecnologías y medios de comunicación en los discursos literarios.

De tal manera que la poética de Rodrigo Fresán es representante de la tradición literaria cosmopolita que busca la internacionalización de la literatura por encima de cualquier búsqueda de aceptación canónica o social. Fresán accede a una de las condiciones más primitivas de la literatura: la irrealidad, vista no como una puerta de escape, sino como una condición sine qua non para la existencia de la realidad misma, de manera que los límites que existen entre ficción y realidad se diluyen, dando pie a la individualización y al multiperspectivismo, tal como sucede con la mayoría de los personajes de Rodrigo Fresán, individuos que muestran su visión de las cosas, su percepción del mundo o de los mundos y sus galaxias ya desde la muerte, ya desde el coma profundo, ya desde la desaparición por acelerador de partículas. Esto implica la deformación de un discurso, el sabotaje de la oficialidad y el erguimiento de una perspectiva iǵual de épica o trágica que cualquiera: la individualista. De ahí que surjan las interrogantes ¿por qué se escribe? ¿Cómo empezar a contar la historia propia? ¿Cómo terminarla?, atribuyéndole a la literatura el carácter de artificio que la aleja de la experiencia en sí, pero que posibilita la imposición del individuo y su visión de mundo, sobre cualquier discurso oficial y, por ende, canónico.

\section{Referencias}

Benzecry, Claudio E. (2000). El almuerzo de los remeros. Profesionalismo y literatura en la década de los '90. Hispamérica, 87, 17-30.

Bloom, H. (1995). The western canon: the books and school of the ages. New York: Riverhead books.

Borges, J. L. (1998). La memoria de Shakespeare. Madrid: Alianza editorial.

Brown, A. (2010). Cyborgs in latin america. Palgrave McMillan US.

Carpentier, A. (2003). Los pasos recobrados: ensayos de teoría y crítica literaria. Caracas: Biblioteca Ayacuch.

Fornet, J. (2005). Nuevos paradiǵmas en la narrativa latinoamericana. Latin american studies center, working series, 13.

Fresán, R. (2014). Mantra. Barcelona: Penguin Random House.

Fresán, R. (2017a). El fondo del cielo. Barcelona: Literatura Random House.

Fresán, R. (2017b). Jardínes de Kensington. Barcelona: Literatura Random House.

Fresán, R. (2017c). La parte inventada. Barcelona: Literatura Random House.

Fresán, R. (2018). Historia argentina. Barcelona: Literatura Random House. 
Fuguet, A. y Gómez, S. (Eds.). (1996). McOndo. Barcelona: Mondadori.

Gaffoglio, L. (2014). Rodrigo Fresán: escribir hoy es más arduo, cansador y lento, pero también es más interesante. La nación, 5 de Mayo.

Hargrave, K., y Seminet, G. S. (1998). De Macondo a «McOndo»: nuevas voces en la literatura latinoamericana. Chasqui: revista de literatura latinoamericana, 27(2), $14-26$.

Padilla, I. (2004). McOndo y el crack: dos experiencias grupales. Palabra de América (pp.136-147). Barcelona: Seix Barral.

Palaversich, D. (2000). Rebeldes sin causa. Realismo mágico vs realismo virtual. Hispamérica, 86, 55-70.

Rama, Á. (1981). Novísimos narradores hispanoamericanos en marcha. Montevideo: Marcha Editores.

Rama, Á. (1982). Transculturación narrativa en América latina. México: Siǵlo XXI.

Rama, Á. (2008). La novela en América latina. Santiago de Chile: Universidad Alberto Hurtado.

Rodríguez, C. M. (2012). La fiebre de las antologías: narrativa hispanoamericana en tránsito al siglo XXI. Revista de Crítica Literaria Latinoamericana, 75, 441-464.

Soldán, E. P. (2004). Between tradition \& innovation. The new Latin American narrative. World literature today, 78(3/4), 16-19.

Ureña, P. H. (2006). Seis ensayos en busca de nuestra expresión. Buenos Aires: Editorial Babel. Recuperado de http://www.cielonaranja.com/phuseisensayos.pdf

Volpi, J. (2004). El fin de la narrativa latinoamericana. Revista de crítica literaria latinoamericana, 30(59), 33-42.

Yoon, C. M. de (2012). La fiebre de las antologías: narrativa hispanoamericana en tránsito al siǵlo XXI. Revista de crítica literaria latinoamericana, 441-464. 